\title{
Minimal systemic hypothermia combined with selective head cooling evaluated in a pig model of hypoxia-ischemia
}

\author{
Nicholas Hoque', Xun Liu', Ela Chakkarapani' and Marianne Thoresen ${ }^{1,2}$
}

BACKGROUND: Selective head cooling (SHC) with moderate hypothermia (HT) and whole-body cooling are beneficial following perinatal asphyxia. SHC with systemic normothermia (NT) or minimal HT is under-investigated, could obviate systemic complications of moderate $\mathrm{HT}$, and be applicable to preterm infants. We hypothesized that minimal systemic HT with SHC following hypoxia-ischemia (HI) would be neuroprotective compared with systemic NT.

METHODS: Newborn pigs underwent global HI causing permanent brain injury before being randomized to NT (rectal temperature $\left.\left(T_{\text {rectal }}\right) 38.5^{\circ} \mathrm{C}\right)$ or minimal $H T\left(T_{\text {rectal }} 37.0^{\circ} \mathrm{C}\right)$ with SHC (cooling cap and body wrap) for $48 \mathrm{~h}$ followed by $24-\mathrm{h}$ NT with 72-h survival.

RESULTS: SHC did not reduce global or regional neuropathology score when correcting for insult severity or compared with a NT group matched for $\mathrm{Hl}$ severity but increased mortality by $26 \%$. During $48 \mathrm{~h}$, the $\mathrm{SHC}$ mean $\pm \mathrm{SD} T_{\text {rectal }}$ was $37.0 \pm 0.2^{\circ} \mathrm{C}$, and $T_{\text {deep brain }}$ and $T_{\text {superficial brain }}$ were $35.0 \pm 1.1^{\circ} \mathrm{C}$ and $31.5 \pm 1.6$ ${ }^{\circ} \mathrm{C}$, respectively, with stable $T_{\text {brain }}$ achieved $\geq 3 \mathrm{~h}$ after starting cooling.

CONCLUSION: This is the first study in newborn pigs of minimal systemic HT with SHC for $48 \mathrm{~h}$ and a further $24 \mathrm{~h}$ of NT following $\mathrm{HI}$. Mortality was increased in the cooled group with no neuroprotection in survivors.

$\mathbf{T}$ herapeutic hypothermia (HT) using whole-body cooling (WBC) to a rectal temperature $\left(T_{\text {rectal }}\right)$ of $33.5^{\circ} \mathrm{C}$ or selective head cooling (SHC) with moderate systemic $\mathrm{HT}$ to $34.5^{\circ} \mathrm{C}$ is the only effective treatment for hypoxic ischemic encephalopathy (HIE) in term infants (1). HIE also occurs in preterm infants and HT trials are planned (e.g., Preemie Hypothermia for Neonatal Encephalopathy, NCT01793129) but concerns remain about systemic adverse effects (2-4). SHC without moderate systemic HT is under-investigated and is suggested to reduce potential systemic complications of whole body-HT. Reducing deep-brain temperature ( $\left.T_{\text {deep brain }}\right)$ using SHC in term infants is difficult but may be easier in preterm infants with their smaller head size, thinner skin, and skull (5). In newborn pigs, $T_{\text {dee brain }}$ is within $1{ }^{\circ} \mathrm{C}$ of core temperature at normothermia (NT) but during SHC there is a gradient of between 3 and
$7{ }^{\circ} \mathrm{C}(6-9)$. SHC may offer an advantage over WBC because different brain regions may have different optimum temperatures for neuroprotection (9-11).

Short-term SHC with systemic NT is possible experimentally but neuroprotection has not been assessed using an adequate treatment period using clinically available equipments (12-14). We showed previously that SHC combined with moderate systemic $\mathrm{HT}$ to $33.5^{\circ} \mathrm{C}$ was neuroprotective using a global model of perinatal hypoxia-ischemia (HI) in the newborn pig (8). We hypothesized that minimal systemic HT $\left(1.5^{\circ} \mathrm{C}\right.$ below core temperature) combined with SHC for $48 \mathrm{~h}$ would be neuroprotective compared with systemic NT using a validated neuropathology score.

\section{RESULTS}

There were no differences in age, weight, sex distribution or baseline arterial $\mathrm{pH}$, lactate, and blood glucose between groups (Table 1).

\section{Mortality and Neuropathology}

The HT group was compared with two NT groups: $\mathrm{NT}_{\mathrm{R}}$, which was randomized to the $\mathrm{HT}$ group, and $\mathrm{NT}_{\mathrm{M}}$, which was severity-matched to the survivors in the HT group. Mortality was higher in the HT compared with the $\mathrm{NT}_{\mathrm{R}}$ group (43 vs. $17 \%, P<0.01$ ), usually due to cardiovascular collapse and the mean \pm SD time until death was $53 \mathrm{~h} \pm 7\left(\mathrm{NT}_{\mathrm{R}}\right)$ and $40 \mathrm{~h} \pm 24$ (HT). Animals with severe insults (total duration of lowamplitude electroencephalogram (LAEEG) $>30 \mathrm{~min}$ out of 45-min HI) did not tolerate $48 \mathrm{~h}$ of HT treatment and died. Where available, all animals had histological evidence of brain injury (Figure 1). There was neither skin injury nor injury or bleeds from the subcutaneously placed needle electroencephalogram (EEG) electrodes. The average neuropathology score in the HT group was lower than that of the $\mathrm{NT}_{\mathrm{R}}$ group, but neuropathology was incomplete in a number of HT animals because of early death (before the end of the 48-h treatment period). The total duration of LAEEG, which is the best predictor of brain injury in this model (15), was shorter for survivors in the $\mathrm{HT}$ group compared with those of the $\mathrm{NT}_{\mathrm{R}}$ group. We used a stepwise linear regression analysis to account for the discrepancy in LAEEG, which revealed arterial $\mathrm{pH}$ at the end of $\mathrm{HI}$ 
Table 1. Clinical characteristics of treatment groups

\begin{tabular}{|c|c|c|c|c|}
\hline Treatment group & $\mathrm{NT}_{\mathrm{R}}$ & $\mathrm{NT}_{\mathrm{M}}$ & HT & $P$ value \\
\hline$n$ & 12 & 14 & 10 & - \\
\hline Female (\%) & 58 & 53 & 40 & 0.7 \\
\hline Weight at start of experiment, $\mathrm{kg}$, mean \pm SD & $1.557 \pm 0.25$ & $1.654 \pm 0.27$ & $1.655 \pm 0.24$ & 0.6 \\
\hline $\mathrm{pH}$ at baseline, mean $\pm \mathrm{SD}$ & $7.47 \pm 0.07$ & $7.48 \pm 0.10$ & $7.52 \pm 0.05$ & 0.3 \\
\hline Blood glucose at baseline, $\mathrm{mmol} / \mathrm{l}$, mean $\pm \mathrm{SD}$ & $6.3 \pm 1.6$ & $7.6 \pm 1.4$ & $7.1 \pm 1.4$ & 0.2 \\
\hline Duration of LAEEG during insult, min, mean \pm SD & $36.7 \pm 8.2$ & $23.8 \pm 2.9$ & $21.8 \pm 3.5$ & $<0.0001^{*}$ \\
\hline $\mathrm{pH}$ at end of insult, mean \pm SD & $7.04 \pm 0.16$ & $7.10 \pm 0.14$ & $7.08 \pm 0.12$ & 0.5 \\
\hline Lactate at end of insult, $\mathrm{mmol} / \mathrm{l}$, mean $\pm \mathrm{SD}$ & $15.0 \pm 1.9$ & $19.1 \pm 3.5$ & $17.2 \pm 2.1$ & $0.006^{\mathrm{a}}$ \\
\hline $\mathrm{MABP}$ during insult, $\mathrm{mmHg}$, mean $\pm \mathrm{SD}$ & $37 \pm 7$ & $45 \pm 7$ & $40 \pm 4$ & $0.007^{b}$ \\
\hline
\end{tabular}

n, number of animals with neuropathology available; HT, hypothermia; LAEEG, low-amplitude electroencephalogram; MABP, mean arterial blood pressure; NT , matched normothermia; $\mathrm{NT}_{\mathrm{R}^{\prime}}$ randomized normothermia; $\mathrm{SD}$, standard deviation.

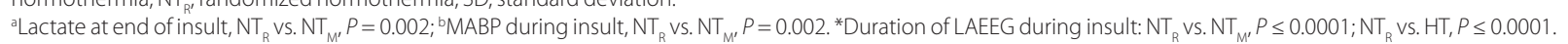

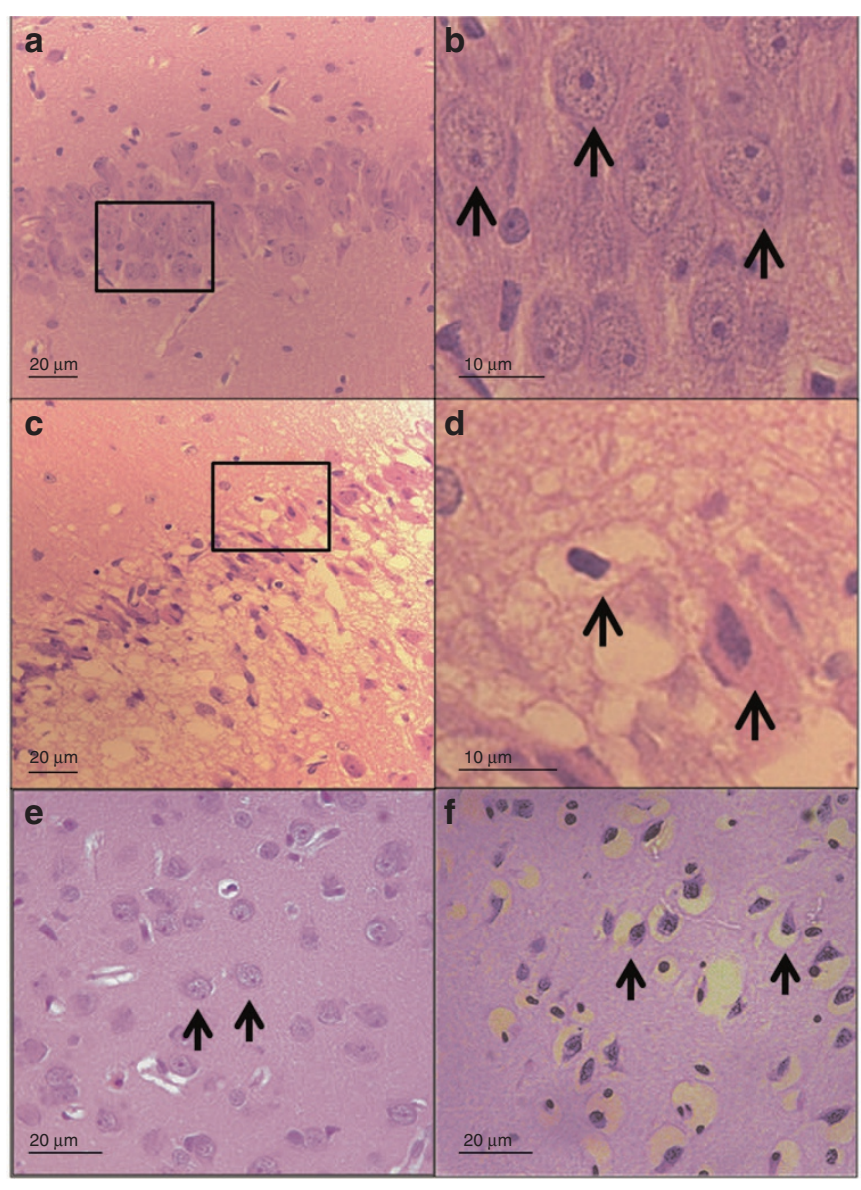

Figure 1. Representative photomicrographs of the hippocampus $C A 1$ and putamen stained with hematoxylin and eosin. (a) Hippocampus CA1 region ( $\times 400$ magnification) showing normal appearance and architecture with (b) detail showing healthy neurons (arrows). (c) Severe ischemic changes in hippocampus with (b) detail showing cytoplasmic shrinkage, nuclear condensation, disruption of tissue architecture, perineuronal vacuolation, and neuropil vacuolation (arrows). (e) Putamen (×630 magnification) with healthy neuronal cells (arrows) and (f) ischemic cells in putamen (arrows). and total duration of LAEEG during HI as significant independent variables predicting the global neuropathology score (Table 2), but there was no significant relationship between the temperature (NT vs. HT) and the global neuropathology score. We corroborated our results by comparing the HT group with a group of historical controls $\left(\mathrm{NT}_{\mathrm{M}}\right)$ matched for the total duration of LAEEG during $\mathrm{HI}$ and arterial $\mathrm{pH}$ at the end of $\mathrm{HI}$ as detailed in the Methods section. There was no difference in the total duration of LAEEG during HI, arterial $\mathrm{pH}$ and lactate at the end of $\mathrm{HI}$, and mean arterial blood pressure (MABP) during HI between the matched groups. There were no significant differences in global or regional neuropathology scores between the $\mathrm{NT}_{\mathrm{M}}$ and HT groups (Figure 2).

\section{Seizures}

Seizures were treated as per the drug protocol and there were no differences in clinical or electrographic seizure incidence between groups $\left(\mathrm{NT}_{\mathrm{R}}: 6\right.$ out of $12, \mathrm{NT}_{\mathrm{M}}: 5$ out of 14 , and $\mathrm{HT}: 1$ out of 10). The presence of seizures and seizure duration were not found to be significant independent predictors of neuropathology score in the stepwise linear regression analysis.

Table 2. Stepwise linear regression model for global neuropathology score in randomized $\mathrm{NT}_{\mathrm{R}}(n=12)$ and $\mathrm{HT}(n=10)$ groups

\begin{tabular}{lccccc} 
Variable & $B$ & SE $B$ & $\beta$ & $t$ & $P$ \\
\hline (Constant) & 23.25 & 8.17 & - & 2.85 & 0.010 \\
$\begin{array}{l}\text { Arterial pH at end of } \\
\text { insult }\end{array}$ & -3.33 & 1.15 & -0.438 & -2.90 & 0.009 \\
$\begin{array}{l}\text { Total duration LAEEG } \\
\text { during insult }\end{array}$ & 0.05 & 0.017 & 0.406 & 2.70 & 0.014 \\
$\begin{array}{l}\text { Model } R^{2}=0.56 \text {, adjusted } R^{2}=0.49 \\
\text { Dep }\end{array}$ & & & & \\
\hline
\end{tabular}

Dependent variable: global neuropathology score; excluded independent variables: temperature (NT or HT), weight, lactate, and base deficit at the end of HI, MABP, and $T_{\text {rectal }}$ during $\mathrm{Hl}$ insult.

$B$, unstandardized coefficient; $\beta$, standardized coefficient; SE $B$, standard error; $t, t$-test statistic. 


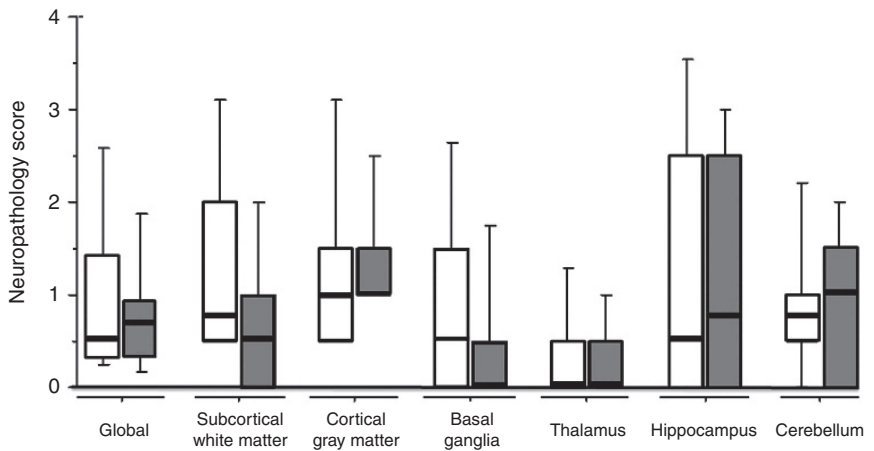

Figure 2. Global and regional neuropathology scores. Box and whisker plot showing median (thick line) and, 25th and 75th (box), and 10th and 90th (whisker) centiles for neuropathology score following 45-min $\mathrm{HI}$ for the $\mathrm{NT}_{\mathrm{M}}$ (white, $n=14$ ) and HT groups (gray, $n=10$ ).

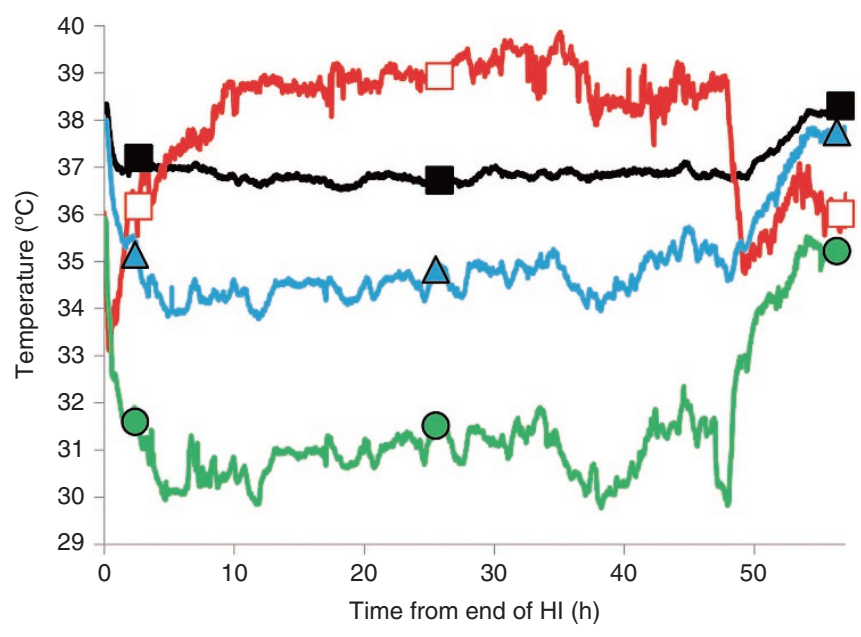

Figure 3. Mean $T_{\text {rectal' }} T_{\text {skin' }}$ and $T_{\text {brain }}$ during $\mathrm{HT}(n=14)$. Mean temperatures during $\mathrm{HT}$ from the end of $\mathrm{HI}$ until the end of rewarming for the group. $T_{\text {rectal }}$ (black, closed square), $T_{\text {skin }}$ (red, open square), $T_{\text {deep brain }}$ (blue, triangle), and $T_{\text {superficial brain }}$ (green, circle).

\section{Temperature}

The mean $\pm \mathrm{SD} T_{\text {rectal }}$ during cooling was $37.0 \pm 0.2{ }^{\circ} \mathrm{C}$ and remained relatively stable with mean $T_{\text {deep brain }}$ of $35.0 \pm 1.1^{\circ} \mathrm{C}$ and $T_{\text {superficial brain }}$ of $31.5 \pm 1.6^{\circ} \mathrm{C}$ (Figure 3 ). A gradient developed between $T_{\text {rectal }}$ beingwarmest, $T_{\text {deepbrain }}$ beingcooler, and $T_{\text {superficialbrain }}$ being coolest with stable brain temperatures achieved $3-4 \mathrm{~h}$ after initiating cooling. The cooling cap water temperature started at $30{ }^{\circ} \mathrm{C}$ and was gradually decreased to $18{ }^{\circ} \mathrm{C}$ whilst maintaining $T_{\text {rectal }}$ at $37^{\circ} \mathrm{C}$. There was a strong negative correlation between the $T_{\text {rectal }}$ to $T_{\text {superficial brain }}$ gradient and the subcortical white matter neuropathology score in HT animals $(r=0.7)$, i.e., the colder the superficial brain, the lesser the subcortical white matter injury (Figure 4). Rewarming after 48-h HT was associated with a rapid increase in brain temperature (Figure 5). $T_{\text {deep }}$ brain and $T_{\text {superficial brain }}$ increased by around $1.8^{\circ} \mathrm{C} / \mathrm{h}$ and $4.6^{\circ} \mathrm{C} / \mathrm{h}$, respectively. Opening the body wrap, which applied body heating during SHC, decreased $T_{\text {rectal }}, T_{\text {deep brain }}$, and $T_{\text {superficial brain }}$ by $2,2.5$, and $3.5^{\circ} \mathrm{C}$, respectively, below steady state showing that using this technique combined with the cooling cap the balance is easily disturbed by opening the body wrap. The increase in $T_{\text {rectal }}$ back to baseline $\left(37^{\circ} \mathrm{C}\right)$ (Figure 5 b) was accompanied

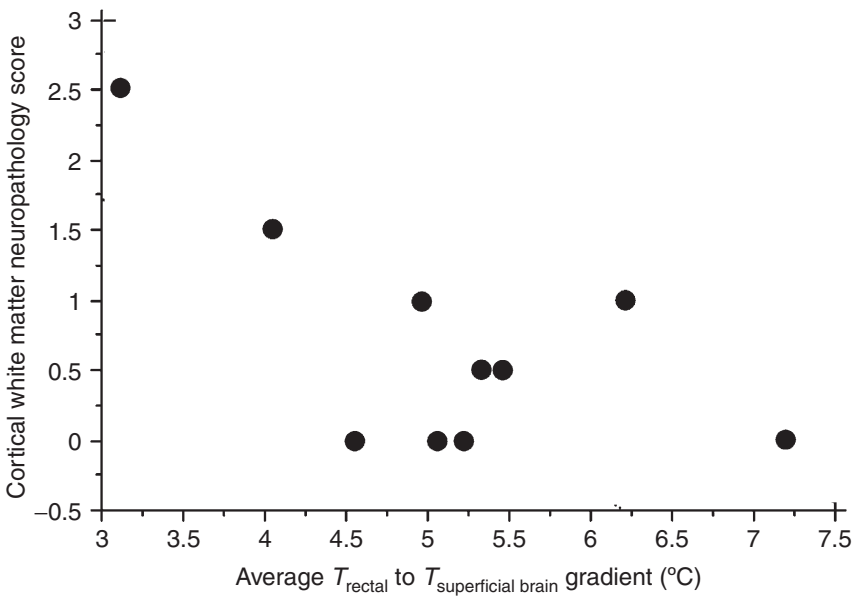

Figure 4. Relationship between average $T_{\text {rectal }}$ to $T_{\text {superficial brain }}$ gradient and subcortical white matter neuropathology score. Scatter plot of individual HT animals $(n=10)$.

by the rapid increase in $T_{\text {deep brain }}\left(3^{\circ} \mathrm{C} / \mathrm{h}\right)$ and $T_{\text {superficial brain }}(4.5$ $\left.{ }^{\circ} \mathrm{C} / \mathrm{h}\right)$.

\section{Cardiovascular Physiology}

The mean \pm SD heart rate (HR) during treatment was significantly lower in the HT group compared with that of both NT groups $\left(\mathrm{NT}_{\mathrm{R}}: 186 \pm 29, \mathrm{NT}_{\mathrm{M}}: 186 \pm 21\right.$, and HT: $124 \pm 21 \mathrm{bpm}$, $P<0.05)$, however, similar at the end of the experiment when all groups were at NT. The mean MABP \pm SD during treatment (0-48 h after $\mathrm{HI})$ was similar between the groups $\left(\mathrm{NT}_{\mathrm{R}}: 60 \pm 10\right.$, $\mathrm{NT}_{\mathrm{M}}: 52 \pm 6$, and HT: $51 \pm 6 \mathrm{mmHg}$ ) as was the proportion of animals receiving inotropes $\left(\mathrm{NT}_{\mathrm{R}}: 9(75 \%), \mathrm{NT}_{\mathrm{M}}: 8(57 \%)\right.$, and HT: 5 animals (50\%)). In animals receiving inotropes, the median interquartile range (IQR) duration of dopamine administration was $1,135 \mathrm{~min}(818-1,219)$ in the $\mathrm{NT}_{\mathrm{R}}$ group, $1,425 \mathrm{~min}(1,290-1,920)$ in the $\mathrm{NT}_{\mathrm{M}}$ group and $1,208 \mathrm{~min}$ (850-1,576) in the HT group.

\section{DISCUSSION}

Minimal systemic HT combined with 48-h SHC following HI increased mortality and did not improve global neuropathological injury score in a newborn pig model. This is the first study of minimal HT combined with SHC in a preclinical survival model of perinatal asphyxia.

$\mathrm{HT}$ by $3-4^{\circ} \mathrm{C}$ is neuroprotective after neonatal encephalopathy in term infants using SHC with moderate systemic HT or WBC (1). Minimal HT $\left(36^{\circ} \mathrm{C}\right)$ had a similar risk of death or poor neurologic function at $180 \mathrm{~d}$ compared with moderate HT $\left(33^{\circ} \mathrm{C}\right)$ in adults after cardiac arrest (16). SHC with minimal systemic HT may obviate the potential adverse effects of systemic HT such as cardiovascular compromise, pulmonary hypertension, infection, and coagulopathy, and be applicable to preterm infants.

\section{Brain Cooling}

Iwata et al. (17) found protection from intraischemic brain HT when $T_{\text {rectal }}$ fell by $1{ }^{\circ} \mathrm{C}$ with 48 -h survival in newborn pigs, but cap water temperatures of $0-10^{\circ} \mathrm{C}$ caused significant scalp 

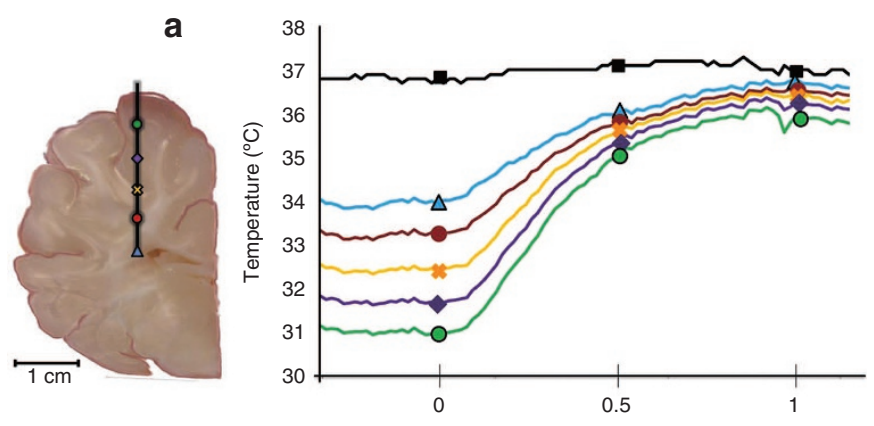

b

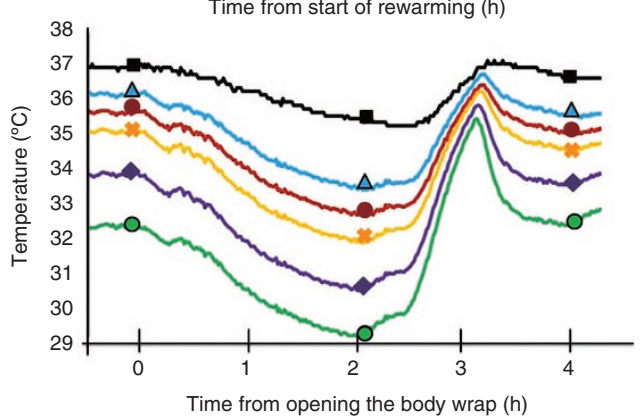

C

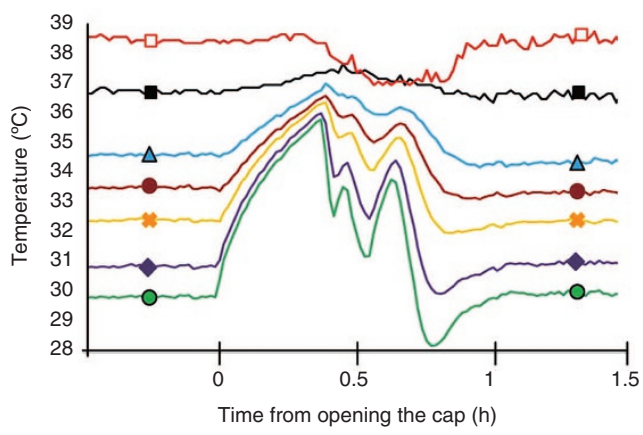

Figure 5. Brain, skin, and rectal temperature from three subjects. (a) $T_{\text {rectal }}$ and $T_{\text {brain }}$ during rewarming in a representative animal. Rewarming starts by discontinuing water flow through the cooling cap and continuing the overhead heating. This animal did not wear the water-perfused body wrap. There was a rapid increase in $T_{\text {brain }}(5 \mathrm{~mm}$ (green, open circle), $10 \mathrm{~mm}$ (purple, diamond), $15 \mathrm{~mm}$ (orange, cross), $20 \mathrm{~mm}$ (brown, closed circle), and $25 \mathrm{~mm}$ (blue, triangle) depth from the brain surface) and loss of the gradient between $T_{\text {rectal }}$ (black, square) and $T_{\text {brain }}$. Inset: coronal brain section illustrating the brain temperature probe position with sensors at 5-mm intervals. (b) Temperature changes in $T_{\text {rectal }}$ and $T_{\text {brain }}$ when the body wrap around the abdomen was opened to manage the umbilical lines. The body wrap heated the body to counteract the cooling effect of the cap (the way the CoolCap was designed to work), and opening it reduced body heating and hence $T_{\text {rectal }}$ and $T_{\text {brain }}$ were reduced. The cooling cap water temperature was initially kept the same. When the cooling cap water temperature was increased to prevent further decreases in $T_{\text {rectal }}$ and $T_{\text {brain }}$, both temperatures rose rapidly with loss of the gradient between them. The gradient was previously maintained by cooling the brain and heating the body at the same time. (c) Temperature changes in $T_{\text {rectal, }} T_{\text {brain' }}$ and $T_{\text {skin }}$ when the cooling cap was opened. This subject received body heating from a combination of the body wrap and overhead heating. $T_{\text {rectal }}$ increased and $T_{\text {brain }}$ increased rapidly when the cooling cap was opened for skin inspection. The instructions for skin care while undergoing SHC with the Cool Cap instructs opening the cap to inspect the skin 12-hourly. This leads to a rapid increase in $T_{\text {brain }}$ due to cessation of scalp cooling and slower increase in $T_{\text {rectal }}$ due to unopposed heating from the body wrap. The additional overhead heating was discontinued to prevent further increase in $T_{\text {rectal }}$ leading to a decrease in $T_{\text {skin }}$ (red, open square). $T_{\text {rectal }}$ and $T_{\text {brain }}$ decreased when the cooling cap was replaced. damage in all subjects. Tooley et al. (12) cooled $T_{\text {deep brain }} 7.7$ ${ }^{\circ} \mathrm{C}$ lower than $T_{\text {rectal }}$ for $8 \mathrm{~h}$ in newborn pigs but did not assess neuroprotection in a short-term survival study. We started treatment at the end of $\mathrm{HI}$ and continued for $48 \mathrm{~h}$ using the equipment currently used in clinical practice. We chose a treatment duration of $48 \mathrm{~h}$ instead of $24 \mathrm{~h}$ used previously in our model to compensate for cooling the brain at a higher temperature than during WBC.

Cooling the deep-brain structures using a cooling cap was limited by the heating capacity of the body wrap to counteract constant cooling from the cap because we challenged the equipment into a situation neither was originally designed for. In our previous much shorter study, we used cap temperatures around $7^{\circ} \mathrm{C}$ cooler than the present study and SHC was balanced by radiant heaters in close proximity to the body, which resulted in high skin temperatures $\left(40^{\circ} \mathrm{C}\right)$ and tendency of hypotension that would be undesirable in clinical practice (12). The purpose-built cooling equipment for SHC and body warming was slow in achieving a balance between brain and body temperature.

\section{Increased Mortality and No Neuroprotection}

Despite lowering $T_{\text {deep brain }}$ by $3.5^{\circ} \mathrm{C}\left(35.0 \pm 1.1^{\circ} \mathrm{C}\right)$ and $T_{\text {superficial }}$ brain by $7^{\circ} \mathrm{C}\left(31.5 \pm 1.6^{\circ} \mathrm{C}\right)$ that would be expected to be neuroprotective from previous studies, we did not observe any benefit on global brain injury. Instead, we found increased mortality in cooled animals and only a trend toward less subcortical white matter injury. In all previous studies with HT under sedation, we used 6-, 12-, or 24-h HT and found neuroprotection $(8,18,19)$ but we chose 48 -h SHC in this study to counteract minimal systemic HT. However, 48-h cooling was not tolerated by those animals suffering severe insults trending toward lower blood pressure and longer duration of inotropic support. Similarly, in humans, 72-h HT is beneficial but a recent randomized study stopped cooling for $120 \mathrm{~h}$ because it was associated with high mortality $(1,20)$. This has important implications for cooling outside trial protocols.

Cooling is more effective if starting early but our method takes $3-4 \mathrm{~h}$ to reduce brain temperature while maintaining $T_{\text {rectal }}$ at $37{ }^{\circ} \mathrm{C}(21)$. The brain HT was obtained after $51 \mathrm{~min}$ when $T_{\text {rectal }}$ was allowed to drop to $34.5^{\circ} \mathrm{C}$ and after $40 \mathrm{~min}$ with WBC $(8,18)$. HT is ineffective in our model if delayed by $3 \mathrm{~h}$, and delayed HT is associated with decreased efficacy in other experimental and clinical studies (22-25).

Systemic inflammation and interplay between organs may be important in the propagation of brain injury (26), and WBC may antagonize cytokines or activate targets that attenuate brain injury (27). SHC combined with minimal HT may not attenuate the systemic inflammatory response as effectively as WBC, and inflammatory mediators may propagate brain injury despite selective brain cooling. In adult stroke patients, plasma levels of interleukin (IL)-6 predicted long-term outcome and WBC suppressed the IL- 6 and IL- 4 response in asphyxiated newborns compared with normothermic infants $(28,29)$. Mobilization of the peripheral immune system and 


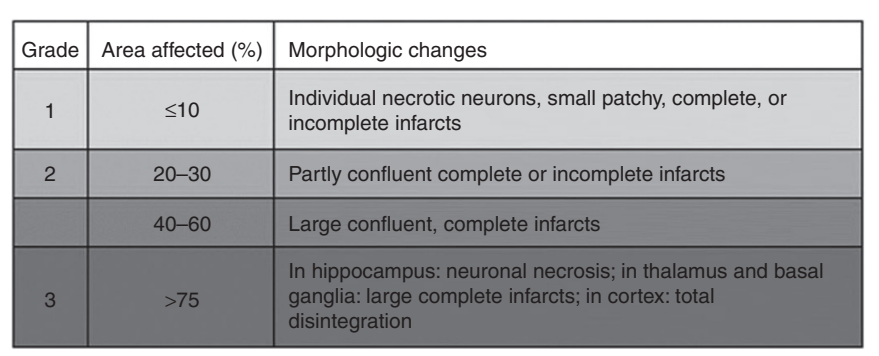

Figure 6. Grading system for regional neuropathology. Reproduced from Table 1 in Thoresen et al. (15). "Incomplete" infarct describes a localized area where necrotic neurons are observed but other cell types including glia and vessels are preserved.

influx of neutrophils is observed in preterm sheep following $\mathrm{HI}$, and the blood-brain barrier is more permeable in newborns particularly in the context of systemic inflammation and may allow the entry of circulating cytokines into the brain $(30,31)$. The influence of systemic responses can be observed more easily using our global $\mathrm{HI}$ model than using a selective cerebral HI model.

\section{Rapid Changes in Brain Temperature}

The brain temperature increased rapidly to approach $T_{\text {rectal }}$ during rewarming from $\mathrm{SHC}$ and also when removing the cap for skin inspection as instructed every $12 \mathrm{~h}$ (Figure 3 ). The rapid perfusion of cooled cerebral structures with warmer blood twice daily and at the end of treatment may be detrimental and certainly rapid rewarming of core temperature is associated with seizures (32). This has implications for current clinical practice of SHC where the cap is removed every $12 \mathrm{~h}$ and sharp rises in brain temperature may occur at least five times during treatment.

\section{Cardiovascular Effects}

The higher skin temperature and peripheral vasodilatation from body heating may explain why there was no net effect on cardiovascular status. This is consistent with SHC with moderate systemic HT in infants where the effect on inotropic support is uncertain (33). The mean HR decreased by 60 bpm during SHC equating to $17 \mathrm{bpm} /{ }^{\circ} \mathrm{C}$ using $T_{\text {deep brain }}$ or $40 \mathrm{bpm} /{ }^{\circ} \mathrm{C}$ using $T_{\text {rectal }}$, and we previously reported that $\mathrm{HT}$ reduces HR by around $10 \mathrm{bpm} /{ }^{\circ} \mathrm{C}$. This suggests that brain temperature is a more important determinant for HR than body temperature, consistent with the temperature-sensing area being in the hypothalamus (34).

\section{Study Limitations}

The findings in preclinical animal models do not always translate successfully but previous work using this model has contributed to changes in clinical practice (8). It has been suggested that external cooling of the term human newborn head is only effective down to a depth of $2 \mathrm{~cm}$ from the scalp (5). We recorded a lowered brain temperature $2.2 \mathrm{~cm}$ from the brain surface in newborn pigs with head circumferences similar to preterm infants at 27 -wk gestation. The differences between species may influence heat exchange and brain temperature.
The pig brain is $2.3 \%$ of total body weight compared with around $15 \%$ in humans at term, which would make the former easier to cool although thinner skin and cranium may make it easier to cool the human brain $(35,36)$.

Randomization to compare brain injury was unsuccessful due to selectively high mortality in cooled animals. In survivors, the duration of LAEEG during HI (an important measure of insult severity analyzed after the experiment) was shorter in the HT compared with the $\mathrm{NT}_{\mathrm{R}}$ group, and we used regression analysis to assess treatment effect. In addition, we compared brain injury in HT animals with short insult duration with a matched group of NT controls that confirmed the findings of the first analysis. Thus, we compared HT with two different NT control groups to increase the validity of our conclusions.

In summary, we cooled the brain with only minimal body HT $\left(1.5^{\circ} \mathrm{C}\right.$ below core temperature). SHC reduced $T$ by $7{ }^{\circ} \mathrm{C}$ from $T_{\text {rectal }}$ and $T_{\text {deep brain }}$ by $2{ }^{\circ} \mathrm{C}$. We found that $48-\mathrm{h}$ minimal systemic HT combined with SHC was not protective and increased mortality following HI compared with systemic NT. It took $\sim 4 \mathrm{~h}$ to cool the brain with this method.

\section{METHODS}

Experiments were carried out under a Home Office licence and approved by the University of Bristol Ethical Review Panel.

\section{Preparation}

Crossbred Landrace pigs were born at term gestation (113-115 d). Experiments were started the first day of life at $16 \pm 5 \mathrm{~h}$ mean $\pm \mathrm{SD}$ postnatal age. Pigs were anesthetized (2\% isoflurane, $33 \% \mathrm{O}_{2}$, and $65 \% \mathrm{~N}_{2} \mathrm{O}$ ), intubated, and ventilated (SLE 2000; SLE, Surrey, UK, with $1-2 \%$ isoflurane, $70 \% \mathrm{~N}_{2} \mathrm{O}$, and $28-29 \% \mathrm{O}_{2}$ ) using end-tidal $\mathrm{CO}_{2}$, transcutaneous $\mathrm{O}_{2}$ saturation, and arterial blood gases analyzed at $37^{\circ} \mathrm{C}$ (i-STAT, Abbott, Birmingham, UK; RapidLab $248 \mathrm{pH} / \mathrm{blood}$ gas analyzer, Siemens Healthcare Diagnostics, Surrey, UK) to maintain $\mathrm{pH}, \mathrm{PCO}_{2}$, and $\mathrm{PO}_{2}$ in the normal range $\left(\mathrm{pH}\right.$ 7.35-7.45, $\mathrm{PCO}_{2}$ 4.5-6 kPa, and $\mathrm{PO}_{2} 10-13 \mathrm{kPa}$ ). The MABP was monitored using an umbilical catheter. A $T_{\text {rectal }}$ probe (reusable YSI 400 series, Criticool, MTRE, Yavne, Israel) was inserted to $6 \mathrm{~cm}$, and a skin temperature probe (Criticool) was sited on a hind limb and animals were maintained at NT for pigs $\left(T_{\text {rectal }} 38.5^{\circ} \mathrm{C}\right)$ using a water-circulated body wrap and temperature unit (Criticool) servo-controlled to $T_{\text {rectal }}$ or a radiant heater. An artificial fontanelle and a burr hole were created in the skull to insert a probe (Thermes, Physitemp Instruments, Clifton, NJ) with multiple sensors measuring cortical $(5 \mathrm{~mm}$ from the brain surface) and deep gray matter/basal ganglia $(25 \mathrm{~mm}$ from the cortex) temperature. Three or five needle electrodes (019-409700 $0.4 \mathrm{~mm}(27 \mathrm{G})$ Viasys Healthcare, Chicago, IL) were inserted subdermally into the scalp with an interelectrode distance of $3 \mathrm{~cm}$ to monitor amplitude-integrated EEG (aEEG/EEG) (aEEG, EEG) (Olympic or Brainz, Natus Medical Incorporated, San Carlos, CA). The gas mixture was changed to $0.7 \%$ halothane, $29.3 \% \mathrm{O}_{2}$, and $70 \%$ nitrogen $30 \mathrm{~min}$ before $\mathrm{HI}$.

\section{Hypoxic-Ischemic Insult}

As previously described inspired $\mathrm{O}_{2}$ was reduced to $\sim 6 \%$ for $45 \mathrm{~min}$, causing depression of the background aEEG activity to below $7 \mu \mathrm{V}$ (LAEEG) (18). The duration of LAEEG out of the total $45 \mathrm{~min}$ correlates with the outcome-severity of the insult (15). The animals were resuscitated in air and anesthesia continued using propofol (4-12 mg/ $\mathrm{kg} / \mathrm{h}$ ) and remifentanil $(20-80 \mathrm{mcg} / \mathrm{kg} / \mathrm{h})$.

\section{Randomization and Inclusion in the Study}

The animals were randomized immediately after the 45 - $\mathrm{min}$ insult to $\mathrm{NT}_{\mathrm{R}}\left(T_{\text {rectal }} 38.5 \pm 0.2{ }^{\circ} \mathrm{C}, n=12\right)$ or $\mathrm{HT}\left(T_{\text {rectal }} 37.0 \pm 0.2{ }^{\circ} \mathrm{C}\right.$ for $48 \mathrm{~h}$, 
$n=14$ ) combined with SHC followed by $24-\mathrm{h}$ NT. The animals needed to survive at least $48 \mathrm{~h}$, which is the treatment period to be included.

\section{Matched Normothermic Treatment Group}

A valid neuropathology assessment was not available for all animals because of significantly more early deaths (before the end of the 48-h treatment period) of $43 \%$ in the HT compared with $17 \%$ in the $\mathrm{NT}_{\mathrm{R}}$ group. The total duration of LAEEG was shorter in the HT than the $\mathrm{NT}_{\mathrm{R}}$ group when animals without pathology score were not included and insult severity was not comparable. Therefore, the HT group was matched with a group of historical controls $\left(\mathrm{NT}_{\mathrm{M}}\right)$ using the total duration of LAEEG during $\mathrm{HI}$ and arterial $\mathrm{pH}$ at the end of $\mathrm{HI}$, which are the two best predictors of brain injury in this model (15). There were 10 animals in the HT group matched with 14 in the $\mathrm{NT}_{\mathrm{M}}$ group that underwent similar preparation, $\mathrm{HI}$, and intensive care apart from temperature control.

\section{Intensive Care}

Care followed protocols as described previously including maintenance fluids (5\% dextrose $/ 0.45 \%$ saline $12 \mathrm{ml} / \mathrm{kg} / \mathrm{h}$ ) and antibiotics (amoxicillin $30 \mathrm{mg} / \mathrm{kg} / 12 \mathrm{~h}$, gentamicin $5 \mathrm{mg} / \mathrm{kg} / 24 \mathrm{~h}$ ) (18). Hypotension (MABP $<40 \mathrm{mmHg}$ for $\geq 10 \mathrm{~min}$ ) was managed with fluid boluses and inotropes in a stepwise manner. Clinical and electrical seizures on continuous EEG/aEEG recordings lasting $>5$ min were treated with anticonvulsants. The seizures were identified on aEEG by an abrupt increase in minimum and maximum amplitude $(>10 \mu \mathrm{V})$ lasting $>20 \mathrm{~s}$ and on EEG by gradual build-up and then decline in frequency and amplitude of repetitive spikes or sharp wave activity. The target blood glucose was 3-8 $\mathrm{mmol} / \mathrm{l}$ and hypoglycemia was managed with a $10 \%$ dextrose 2.5 $\mathrm{mls} / \mathrm{kg}$ bolus and increased glucose delivery up to $12 \mathrm{mg} / \mathrm{kg} / \mathrm{min}$.

\section{Temperature Control}

$T_{\text {rectal }}$ was maintained at $38.5^{\circ} \mathrm{C}$ in the NT group using a servo-controlled water-circulated body wrap (Criticool) or a manually adjusted radiant warmer. In the $\mathrm{HT}$ group, $T_{\text {rectal }}$ was reduced to $37.0^{\circ} \mathrm{C}$ at the end of HI. SHC was achieved using a water-circulated cap used clinically consisting of a network of channels holding $75 \mathrm{ml}$ of water that was applied to the head and snout (Cool Care System Olympic Medical, Seattle, WA) (37). A disposable nappy covered the cap as an insulating layer with a reflective shield (Olympic Medical) covering the head and neck. Water circulated through the cap at $750 \mathrm{ml} / \mathrm{min}$ between 5 and $30{ }^{\circ} \mathrm{C}$ controlled by a mobile cooling unit (Cool Care System). The temperature of water was gradually decreased from 30 ${ }^{\circ} \mathrm{C}$ to a median (IQR) of $18{ }^{\circ} \mathrm{C}(15-21)$ to maintain a gradient between brain and body with stable target $T_{\text {rectal }}$. The body wrap warmed the body and additional overhead heating was used as fine-tuning. SHC and relative body warming continued for $48 \mathrm{~h}$ before rewarming was commenced by stopping water flow through the cap and removing after $1 \mathrm{~h}$. $T_{\text {rectal }}$ was increased from $37.0^{\circ} \mathrm{C}$ to $38.5^{\circ} \mathrm{C}$ over $4.5 \mathrm{~h}$ at 0.3 ${ }^{\circ} \mathrm{C} / \mathrm{h}$. The animals were maintained at $T_{\text {rects }}$ of $38.5^{\circ} \mathrm{C}$ using the servocontrolled body wrap for further $24 \mathrm{~h}$ until kill at $72 \mathrm{~h}$ after HI.

\section{Pathology}

The animals were killed after 72-h survival and brains were perfusion-fixed $(0.9 \% \mathrm{NaCl}$ and $10 \%$ phosphate-buffered formalin) under deep anesthesia. The right (uninstrumented) cerebral hemisphere was blocked at 5 -mm intervals, paraffin-embedded, and $6-\mu \mathrm{m}$ sections from 13 blocks stained with hematoxylin and eosin. A perinatal pathologist who was blinded to treatment and the clinical course assessed brain injury in six regions (cortical gray matter, subcortical white matter, basal ganglia, thalamus, hippocampus, and cerebellum) using a nine-point score from 0.0 to 4.0 with intervals of 0.5 , and a global score was calculated from the mean of regional scores (Figure 6) (15).

\section{Statistical Methods}

Mean (SD) and ANOVA with Bonferonni posthoc test were used for normally distributed continuous data and median (IQR) and the Kruskal-Wallis test was used when data did not have a normal distribution with $P<0.05$ (two-tailed testing) considered significant (IBM SPSS Statistics v21.0, Armonk, NY). The stepwise linear regression analysis was performed with global neuropathology score as the dependent variable using a significance value of 0.05 when allowing independent variables into the regression model.

\section{ACKNOWLEDGMENT}

We are grateful to Helen Porter, a perinatal pathologist, for carrying out the neuropathology scoring.

\section{STATEMENT OF FINANCIAL SUPPORT}

The work was supported by grants from Action Medical Research (UK) (N.H.), SPARKS (London, UK) (X.L. and E.C.), University of Bristol Alumni and Mothercare, the Norwegian Research Council, and the Laerdal Foundation for Acute Medicine (Norway).

Disclosure: We confirm that there are no known conflicts of interest associated with this publication.

\section{REFERENCES}

1. Jacobs SE, Berg M, Hunt R, Tarnow-Mordi WO, Inder TE, Davis PG. Cooling for newborns with hypoxic ischaemic encephalopathy. Cochrane Database Syst Rev 2013;1:CD003311.

2. Volpe JJ. Brain injury in premature infants: a complex amalgam of destructive and developmental disturbances. Lancet Neurol 2009;8:110-24.

3. Logitharajah P, Rutherford MA, Cowan FM. Hypoxic-ischemic encephalopathy in preterm infants: antecedent factors, brain imaging, and outcome. Pediatr Res 2009;66:222-9.

4. SILVERMAN WA, FERTIG JW, BERGER AP. The influence of the thermal environment upon the survival of newly born premature infants. Pediatrics 1958;22:876-86.

5. Van Leeuwen GM, Hand JW, Lagendijk JJ, Azzopardi DV, Edwards AD. Numerical modeling of temperature distributions within the neonatal head. Pediatr Res 2000;48:351-6.

6. Thoresen M, Simmonds M, Satas S, Tooley J, Silver IA. Effective selective head cooling during posthypoxic hypothermia in newborn piglets. Pediatr Res 2001;49:594-9.

7. Iwata S, Iwata O, Thornton JS, et al. Superficial brain is cooler in small piglets: neonatal hypothermia implications. Ann Neurol 2006;60:578-85.

8. Tooley JR, Satas S, Porter H, Silver IA, Thoresen M. Head cooling with mild systemic hypothermia in anesthetized piglets is neuroprotective. Ann Neurol 2003;53:65-72.

9. Laptook AR, Shalak L, Corbett RJ. Differences in brain temperature and cerebral blood flow during selective head versus whole-body cooling. Pediatrics 2001;108:1103-10.

10. Iwata O, Thornton JS, Sellwood MW, et al. Depth of delayed cooling alters neuroprotection pattern after hypoxia-ischemia. Ann Neurol 2005;58:75-87.

11. Rutherford MA, Azzopardi D, Whitelaw A, et al. Mild hypothermia and the distribution of cerebral lesions in neonates with hypoxic-ischemic encephalopathy. Pediatrics 2005;116:1001-6.

12. Tooley JR, Eagle RC, Satas S, Thoresen M. Significant head cooling can be achieved while maintaining normothermia in the newborn piglet. Arch Dis Child Fetal Neonatal Ed 2005;90:F262-6.

13. Iwata O, Iwata $S$, Tamura M, Nakamura T, Sugiura M, Ogiso Y. Brain temperature in newborn piglets under selective head cooling with minimal systemic hypothermia. Pediatr Int 2003;45:163-8.

14. Gelman B, Schleien CL, Lohe A, Kuluz JW. Selective brain cooling in infant piglets after cardiac arrest and resuscitation. Crit Care Med 1996;24: 1009-17.

15. Thoresen M, Haaland K, Løberg EM, et al. A piglet survival model of posthypoxic encephalopathy. Pediatr Res 1996;40:738-48.

16. Nielsen N, Wetterslev J, Cronberg T, et al.; TTM Trial Investigators. Targeted temperature management at $33^{\circ} \mathrm{C}$ versus $36^{\circ} \mathrm{C}$ after cardiac arrest. N Engl J Med 2013;369:2197-206.

17. Iwata O, Iwata S, Tamura M, et al. Early head cooling in newborn piglets is neuroprotective even in the absence of profound systemic hypothermia. Pediatr Int 2003;45:522-9.

18. Chakkarapani E, Dingley J, Liu X, et al. Xenon enhances hypothermic neuroprotection in asphyxiated newborn pigs. Ann Neurol 2010;68:330-41.

19. Haaland K, Løberg EM, Steen PA, Thoresen M. Posthypoxic hypothermia in newborn piglets. Pediatr Res 1997;41(4 Pt 1):505-12. 


\section{Articles Hoque et al.}

20. Shankaran S, Laptook AR, Pappas A, McDonald SA, Das A, Tyson JE, et al. Effect of depth and duration of cooling on deaths in the NICU among neonates with hypoxic ischemic encephalopathy: a randomized clinical trial. JAMA 2014; 312:2629e39.

21. Thoresen M, Tooley J, Liu X, et al. Time is brain: starting therapeutic hypothermia within three hours after birth improves motor outcome in asphyxiated newborns. Neonatology 2013;104:228-33.

22. Thoresen M. Hypothermia after perinatal asphyxia: selection for treatment and cooling protocol. J Pediatr 2011;158:Suppl 2:e45-9.

23. Gunn AJ, Bennet L, Gunning MI, Gluckman PD, Gunn TR. Cerebral hypothermia is not neuroprotective when started after postischemic seizures in fetal sheep. Pediatr Res 1999;46:274-80.

24. Iwata O, Iwata S, Thornton JS, et al. "Therapeutic time window" duration decreases with increasing severity of cerebral hypoxia-ischaemia under normothermia and delayed hypothermia in newborn piglets. Brain Res 2007;1154:173-80.

25. Karlsson M, Tooley JR, Satas S, et al. Delayed hypothermia as selective head cooling or whole body cooling does not protect brain or body in newborn pig subjected to hypoxia-ischemia. Pediatr Res 2008;64:74-8.

26. Hagberg H, Mallard C, Ferriero DM, et al. The role of inflammation in perinatal brain injury. Nat Rev Neurol 2015 (doi: 10.1038/nrneurol.2015.13).

27. Silverstein FS, Barks JD, Hagan P, Liu XH, Ivacko J, Szaflarski J. Cytokines and perinatal brain injury. Neurochem Int 1997;30:375-83.

28. Smith CJ, Emsley HC, Gavin CM, et al. Peak plasma interleukin-6 and other peripheral markers of inflammation in the first week of ischaemic stroke correlate with brain infarct volume, stroke severity and long-term outcome. BMC Neurol 2004;4:2.
29. Róka A, Bekő G, Halász J, et al. Changes in serum cytokine and cortisol levels in normothermic and hypothermic term neonates after perinatal asphyxia. Inflamm Res 2013;62:81-7.

30. Jellema RK, Lima Passos V, Zwanenburg A, et al. Cerebral inflammation and mobilization of the peripheral immune system following global hypoxia-ischemia in preterm sheep. J Neuroinflammation 2013;10:13.

31. Stolp HB, Dziegielewska KM, Ek CJ, Potter AM, Saunders NR. Long-term changes in blood-brain barrier permeability and white matter following prolonged systemic inflammation in early development in the rat. Eur J Neurosci 2005;22:2805-16.

32. Battin M, Bennet L, Gunn AJ. Rebound seizures during rewarming. Pediatrics 2004;114:1369.

33. Battin MR, Thoresen M, Robinson E, Polin RA, Edwards AD, Gunn AJ; Cool Cap Trial Group. Does head cooling with mild systemic hypothermia affect requirement for blood pressure support? Pediatrics 2009;123:1031-6.

34. Chakkarapani E, Thoresen M, Liu X, Walloe L, Dingley J. Xenon offers stable haemodynamics independent of induced hypothermia after hypoxiaischaemia in newborn pigs. Intensive Care Med 2012;38:316-23.

35. Chuntananukoon S, Naiborhu A, Setiabudi M, Sheng HP, Huggins RA. Growth of the pig: patterns of changes in electrolytes, water, and protein. Growth 1976;40:99-106.

36. Laptook AR, Corbett RJ, Nguyen HT, Peterson J, Nunnally RL. Alterations in cerebral blood flow and phosphorylated metabolites in piglets during and after partial ischemia. Pediatr Res 1988;23:206-11.

37. Gluckman PD, Wyatt JS, Azzopardi D, et al. Selective head cooling with mild systemic hypothermia after neonatal encephalopathy: multicentre randomised trial. Lancet 2005;365:663-70. 